\title{
APSIC guidelines for the prevention of surgical site infections
}

\author{
Moi Lin Ling ${ }^{1 *} \mathbb{D}$, Anucha Apisarnthanarak ${ }^{2}$, Azlina Abbas ${ }^{3}$, Keita Morikane ${ }^{4}$, Kil Yeon Lee ${ }^{5}$, Anup Warrier ${ }^{6}$ and \\ Koji Yamada ${ }^{7}$
}

\begin{abstract}
Background: The Asia Pacific Society of Infection Control (APSIC) launched the APSIC Guidelines for the Prevention of Surgical Site Infections in 2018. This document describes the guidelines and recommendations for the setting prevention of surgical site infections (SSIs). It aims to highlight practical recommendations in a concise format designed to assist healthcare facilities at Asia Pacific region in achieving high standards in preoperative, perioperative and postoperative practices.

Method: The guidelines were developed by an appointed workgroup comprising experts in the Asia Pacific region, following reviews of previously published guidelines and recommendations relevant to each section.

Results: It recommends that healthcare facilities review specific risk factors and develop effective prevention strategies, which would be cost effective at local levels. Gaps identified are best closed using a quality improvement process. Surveillance of SSIs is recommended using accepted international methodology. The timely feedback of the data analysed would help in the monitoring of effective implementation of interventions.

Conclusions: Healthcare facilities should aim for excellence in safe surgery practices. The implementation of evidence-based practices using a quality improvement process helps towards achieving effective and sustainable results.
\end{abstract}

Keywords: Surgical site infection, SSI, Prevention, Safe surgery

\section{Introduction}

The incidence of SSI globally varies from $0.9 \%$ of cumulative SSI rate in the USA (NHSN 2014), to $2.6 \%$ in Italy, $2.8 \%$ in Australia (2002-13, VICNISS), 2.1\% in Republic of Korea (2010-11) to 6.1\% in Low Middle Income Countries (LMIC) (WHO, 1995-2015) and 7.8\% in South East Asia (SEA) \& Singapore (pooled incidence from 2000 to 2012) [personal communication]. What definitely stands apart is the very high incidence rates in LMIC and SEA compared to the USA, Europe and Australia. This highlights the need for the SEAsian countries to look at the specific risk factors and develop effective prevention strategies, which would be cost effective at local levels. A summary of common general risk factors may be seen in Table 1 .

\footnotetext{
* Correspondence: ling.moi.lin@singhealth.com.sg

${ }^{1}$ Infection Prevention \& Epidemiology, Singapore General Hospital, Singapore 169608, Singapore

Full list of author information is available at the end of the article
}

The full APSIC Guidelines for the Prevention of Surgical Site Infections is available at https://apsic-apac.org as reference to guide practice. It is developed to assist countries to implement best practices to prevent SSIs esp. in low resource setting.

\section{Review workgroup composition}

APSIC convened experts in Infection Prevention and surgical discipline from Asia Pacific region to develop the APSIC Guidelines for the Prevention of Surgical Site Infections. The members of this workgroup are the authors of this paper.

\section{Literature review and analysis}

For the development of this APSIC guideline, the workgroup reviewed previously published guidelines (e.g. WHO, CDC, Cochrane, etc.) and recommendations relevant to each section and performed computerized literature searches using PubMed. Examples of key search

(c) The Author(s). 2019 Open Access This article is distributed under the terms of the Creative Commons Attribution 4.0 International License (http://creativecommons.org/licenses/by/4.0/), which permits unrestricted use, distribution, and reproduction in any medium, provided you give appropriate credit to the original author(s) and the source, provide a link to the Creative Commons license, and indicate if changes were made. The Creative Commons Public Domain Dedication waiver (http://creativecommons.org/publicdomain/zero/1.0/) applies to the data made available in this article, unless otherwise stated. 
Table 1 Risk factors for SSIs

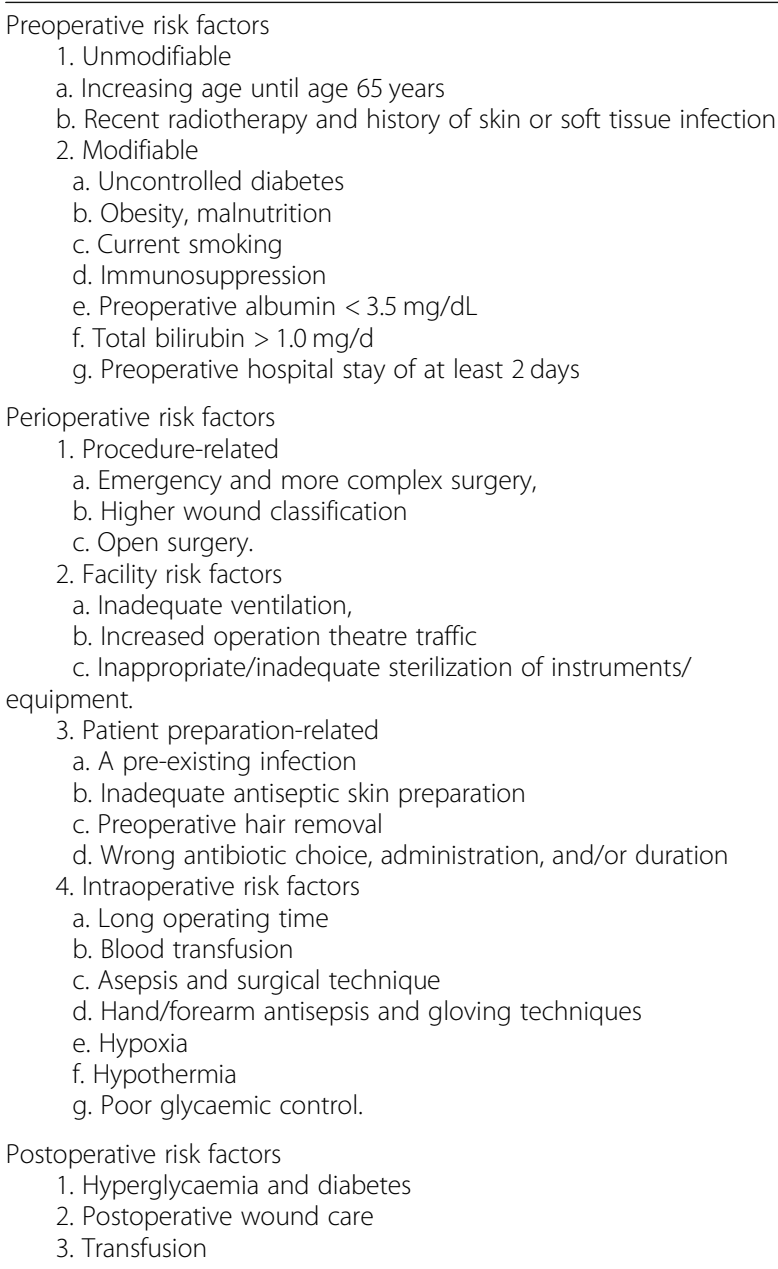

terms used include SSI, prevention and the various topics reviewed.

\section{Process}

The workgroup met on 2 occasions as well as discussed via email correspondences to complete the development of the guideline. Criteria for grading the strength of recommendation and quality of evidence are described in Table 2. The draft was then submitted to two external reviewers, APSIC Executive Committee and national Infection Control societies in Asia Pacific. Comments obtained were then reviewed by the workgroup for necessary edits, following which the final copy was circulated for approval and endorsement by the APSIC Executive Committee and national societies from the Asia Pacific region.

\section{Recommendations for surveillance of surgical site infections (SSIs)}

Surveillance is a systematic methodology which includes monitoring of a specific event, collection and analysis of necessary data associated with the event, and the timely feedback to clinical staff who can implement evidencebased strategies to improve outcomes by decreasing the incidence of the event. Surveillance of SSI with feedback of appropriate data to surgeons and other healthcare workers involved in the care of those undergoing operative procedures has been shown to be an important component of strategies to reduce the risk of SSIs $[1,2]$. A successful surveillance program includes the use of standardized SSI definitions and surveillance methods, stratification of SSI rates according to risk factors associated with SSI development, and timely feedback of data [3].

\section{Perform surveillance of SSIs using accepted international methodology. (IIB)}

\section{Recommendations for pre-operative preventive measures} Pre-operative bath

It is generally accepted that preoperative bathing with soap (antimicrobial or non-antimicrobial) is beneficial prior to surgery, despite the lack of study comparing preoperative bath versus no-preoperative bath on the occurrence of SSIs.

Although recommendations on preoperative bathing in relation to time of administration and the most effective protocol for perioperative bath remains an unresolved issue, it is advisable to take at least 2 baths pre-operatively [4]. Countries with high incidence of multidrug resistant organisms may want to consider the use of an antiseptic instead of plain soap as a preoperative bath. In some Asian countries where allergy to chlorhexidine ( $\mathrm{CHG}$ ) is common or $\mathrm{CHG}$ is not available, alternative agents such as octenidine may be used.

1. It is necessary for patients who will undergo surgery to have at least 1 preoperative bath with soap (antimicrobial or non-antimicrobial). (IIB)

\section{Mechanical bowel preparation (MBP) and oral antibiotics for elective colorectal surgery in adults}

Oral antibiotics have been used to decrease the luminal bacterial load since the 1930s, but it does not decrease SSI. Similarly, oral or intravenous antibiotics alone showed suboptimal effects. A 2014 Cochrane review also recommended that antibiotics should be administered both orally with mechanical bowel preparation and intravenously in $1 \mathrm{~h}$ before surgery to reduce SSIs [5].

1. Combination mechanical bowel preparation and oral antibiotic preparation are recommended for all elective colorectal surgery in adults. (IA)

\section{Hair removal}

There are several methods to remove hair at the surgical site preoperatively. Hair removal by shaving and the 
Table 2 Categories for strength of each recommendation

\begin{tabular}{|c|c|}
\hline \multicolumn{2}{|r|}{ Categories for strength of each recommendation } \\
\hline CATEGORY & DEFINITION \\
\hline A & Good evidence to support a recommendation for use. \\
\hline B & Moderate evidence to support a recommendation for use. \\
\hline C & Insufficient evidence to support a recommendation for or against use \\
\hline D & Moderate evidence to support a recommendation against use. \\
\hline $\mathbf{E}$ & Good evidence to support a recommendation against use. \\
\hline \multicolumn{2}{|r|}{ Categories for quality of evidence on which recommendations are made } \\
\hline GRADE & DEFINITION \\
\hline $\mathbf{I}$ & Evidence from at least one properly randomized, controlled trial. \\
\hline II & $\begin{array}{l}\text { Evidence from at least one well-designed clinical trial without randomization, } \\
\text { from cohort or case-controlled analytic studies, preferably from more than one } \\
\text { centre, from multiple time series, or from dramatic results in uncontrolled } \\
\text { experiments. }\end{array}$ \\
\hline III & $\begin{array}{l}\text { Evidence from opinions of respected authorities on the basis of clinical } \\
\text { experience, descriptive studies, or reports of expert committees. }\end{array}$ \\
\hline
\end{tabular}

night before an operation is associated with and increased risk of SSI. Shaving and/or clipping can cause microscopic cuts in the skin that later serve as foci for bacterial multiplication $[6,7]$.

1. Hair removal should be avoided unless hair interferes with the operative procedure. (IIIB).

2. If hair removal is necessary, a razor should be avoided and an electric clipper should be used. (IA).

3. No recommendation regarding the timing of hair removal by clipper is made. (IIIC).

\section{Methicillin-resistant Staphylococcus aureus (MRSA) screening and decolonization}

It is well recognized that MRSA colonization is associated with worse outcomes and a higher risk for both MRSA SSI and overall SSl. The use of MRSA bundle comprising of screening, decolonization, contact precautions, and vancomycin-containing antibiotic prophylaxis was associated with decreased rates of SSI where there was high compliance with the bundle strategies [8-10].

1. Hospitals should evaluate their SSI, Staphylococcus aureus (S. aureus) and MRSA rates, and mupirocin resistant rate, if available, to determine whether implementation of a screening program is appropriate. (IIB)
2. Patients undergoing cardiothoracic and orthopedic surgery with known nasal carriage of $S$. aureus should receive perioperative intranasal application of mupirocin $2 \%$ ointment with or without a combination of $\mathrm{CHG}$ body wash. (IA)

\section{Surgical hand/forearm preparation}

The objective of cleaning hands and forearms prior to surgery is to reduce the bioburden of bacteria on the skin of the surgical team. The second objective is to inhibit the growth of bacteria. Hands and forearms should undergo a surgical scrub with a surgical antiseptic. When using alcohol-based hand rub (ABHR) solutions containing $60-80 \%$ alcohol is recommended. Water quality may be compromised with the use of tap aerators where these are known to be easily colonized with nonfermentative Gram-negative bacteria e.g. Pseudomonas aeruginosa, Acinetobacter baumannii, etc. Hence, where there are issues with the quality of water used in rinsing hands after hand scrubbing, hand rubbing with $A B H R$ agent is a suitable alternative [11-13].

1. Surgical hand preparation is to be performed either by scrubbing with a suitable antiseptic soap and water or a suitable ABHR before donning sterile gown and gloves. (IA) 
2. ABHR used in surgical hand preparation should comply with EN 12791 or ASTM E-1115 standards. (IIIA)

3. Where the quality of water used is not assured, surgical hand rub with ABHR is recommended. (IIIB)

\section{Skin antiseptic}

Current evidence suggested that alcohol-based preparations are more effective in reducing SSI than aqueous preparations, and should be used, unless contraindicated $[14,15]$. Alcohol has a rapid bactericidal effect, albeit with the lack of persistent antibacterial effect. The benefit of iodine or chlorhexidine and alcohol solutions is prolonged bactericidal activity [16].

1. Alcohol based skin antiseptic preparations should be used, unless contraindicated. (IA)

\section{Surgical prophylaxis}

Current guidelines suggest the use of narrow spectrum antibiotics, such as cefazolin for most surgical procedures, or cefoxitin for abdominal surgery, as surgical antimicrobial prophylaxis. In situations where the incidence of MRSAassociated SSI is high or in case/s of penicillin allergy, vancomycin or fluoroquinolone can be used as an alternative. Current evidence supports the administration of an antimicrobial for surgical prophylaxis within $1 \mathrm{~h}$ before incision or before inflation of a tourniquet in orthopaedic procedures, or within $2 \mathrm{~h}$ for vancomycin or fluoroquinolones, because of their recommended infusion times [17, 18]. In most cases, it is recommended that a single dose of surgical antimicrobial prophylaxis is adequate.

1. Administration of prophylaxis antimicrobials should only be performed when indicated. (IA)

2. Prophylactic antimicrobials should be administered within $1 \mathrm{~h}$ before incision for all antimicrobials except vancomycin and fluoroquinolones where it should be administered within $2 \mathrm{~h}$. (IA)

3. Re-dosing should be considered to maintain adequate tissue levels based on agent half-life. (IA)

4. A single dose of antimicrobial prophylactic is adequate for most surgical procedures. (IA)

\section{Nutrition}

Changes in host immunity may increase a patient's susceptibility to SSIs and malnutrition may contribute to poor surgical outcomes, including delayed recovery, morbidity and mortality, prolonged hospital stay, increased health care costs and readmission. Meta-analysis and randomized controlled studies do not consistently show either benefit or harm when comparing standard versus enhanced nutritional support in reducing the risk of SSIs
[19-22]. Underweight patients undergoing major surgical procedures, especially oncology and cardiovascular operations, however, may benefit from enhanced nutritional support.

1. Underweight patients undergoing major surgical procedures, especially oncology and cardiovascular operations, may benefit from the administration of oral or enteral multiple nutrient-enhanced nutritional formulas for the purpose of preventing SSI. (IIIC)

\section{Glycemic control}

One of the commonest surgical complications in patients with pre-existing diabetes mellitus and hyperglycemia is infection, with superficial surgical site infections (SSIs), deep wound infections, surgical space abscesses, urinary tract infections and pneumonia accounting for a large percentage of infectious complications. The American Diabetes Association defines poorly controlled diabetes as having a target HbA1c level of $\geq 8 \%$ [23]. Using this threshold, studies have shown a higher occurrence of postoperative wound infections in cardiac and orthopaedic patients who had HbA1C levels of $\geq 8 \%[24,25]$. To optimize the care of the patient with diabetes and reduce the risk of complications, a team-oriented approach to treatment is highly recommended [26-28].

1. Preoperative HbA1C levels should be less than $8 \%$. (IIIC)

\section{Recommendations for intra-operative preventive measures \\ Normothermia}

Exposure of large surfaces of skin to cold temperatures in the operating room can cause hypothermia. Hypothermia results in patients waking with chills and shivering, and also raises the risk for other complications such as SSI [29-32]. To avoid these complications, warming systems to transfer heat to a patient's body are used. Several different methods are available, including a forced-air warming system, water bed system, and passive warming system such as blankets.

\section{Maintain perioperative normothermia by using} active warming devices. (IB)

\section{Normovolemia}

Hypovolemia and reduced cardiac output theoretically trigger musculocutaneous and splanchnic vasoconstriction, causing hypoperfusion and tissue hypoxia. Hemodynamic goal-directed therapy, a treatment based on the titration of fluid and inotropic drugs infused to physiologic flow-related end points, is shown to 
significantly reduce SSIs by $42 \%$ in a systematic review $[33,34]$.

1. Hemodynamic goal-directed therapy is recommended to reduce surgical site infection. (IA)

\section{Irrigation}

Wound irrigation is considered to be one of the most useful SSI prevention methods by many surgeons. We agree with WHO and NICE that there is inadequate evidence to comment on this and concur with WHO that antibiotic irrigation for SSI prevention should be avoided [35, 36].

1. There is insufficient evidence to recommend for or against saline of incisional wounds before closure for the purpose of preventing SSI. (IIC).

2. Avoid using antimicrobial agents to irrigate the incisional wounds before closure to reduce the risk of SSI. (IA).

\section{Antimicrobial impregnated sutures}

The latest meta-analysis by Leaper et al., focusing on the cost savings from SSI prevented with addition of antimicrobial sutures as a preventive measure (used in all classes of surgeries), suggests benefits [37].

1. Where there are high SSI rates in clean surgeries, in spite of basic preventive measures, individual centers may consider the use of antimicrobial impregnated sutures. (IIB)

\section{Drapes}

In various guidelines, it is generally accepted not to recommend non-iodine- impregnated adhesive incise drapes, since it is associated with SSI risk. However, in several observational studies especially in clean surgeries, marked SSI reduction reported with the proper use of iodineimpregnated drapes [38-42]. Considering the promising effect of controlling skin recolonization, and the fact that bacterial wound contamination may be directly linked to SSI, we believe that the use of iodine- impregnated adhesive incise drapes may be beneficial. Based on the above evidence, we do recommend their use when necessary, especially in orthopedic and cardiac surgeries.

1. When using adhesive incise drapes, do not use noniodophor-impregnated drapes for surgery as they may increase the risk of surgical site infection. (IE).

2. In orthopedic and cardiac surgical procedures where adhesive incise drapes are used, consider using an iodophor-impregnated incise drape, unless the patient has an iodine allergy or other contraindication. (IIB).

\section{Wound protectors}

In the WHO Global Guidelines for the prevention of SSI, the expert panel concluded that the use of a woundprotector device (single-ring or double-ring) was associated with a significantly lower risk of SSI than with conventional wound protection (OR 0.42; 95\% CI 0.280.62). Unfortunately, the quality of evidence was too low to justify a recommendation to routinely use wound protectors. In resource limited countries, these single use devices may be financially prohibitive [10, 43-45].

1. Careful evaluation of wound protectors needs to be done before introducing the use of wound protectors as a routine measure to reduce SSI. (IIIC)

\section{Vancomycin powder}

We concur with the Centers for Disease Control and Prevention $(\mathrm{CDC})$, where in its latest guidelines strongly recommended not to apply antimicrobial agents (i.e. ointments, solutions, or powders) to the surgical incision for the prevention of SSI [46]. Though many studies provide supportive results, several serious concerns exist regarding their study designs, including the randomized controlled trials (RCTs) $[47,48]$. With global concern on antimicrobial resistance, we will need to discourage the unnecessary resistance pressure associated with use, leading to vancomycin resistant Staphylococcus aureus (VRSA). Hence, vancomycin powder is not recommended for the purpose of preventing SSIs at this point, including spinal surgery.

1. Do not apply vancomycin powder into the surgical site for prevention of surgical site infection, including spine surgery. (IC)

\section{Laminar air flow}

Heterogeneity is seen with data published, and lack of standardization is noted in the surveillance methods and registers used regarding the use of laminar air flow and its association with SSI. In the latest meta-analysis from the WHO, with some additional studies, the risk for deep SSI in association with laminar air flow showed no significant difference compared with a conventional air flow system, with OR: 1.08 (95\% CI $0.77-1.52, p=0.65$ ) for knee arthroplasty, OR: 1.29 (95\% CI 0.98-1.71, $p=$ $0.07)$ for hip arthroplasty, and OR: $0.75(95 \%$ CI $0.43-$ 1.33, $p=0.33$ ) for abdominal and open vascular surgeries. Therefore, WHO has suggested laminar air flow is not required to reduce the risk of SSI for patients undergoing total arthroplasty surgery, and laminar air flow is not required in new operating rooms. Due to the high expense, laminar air flow is not considered necessary for installation in new operating rooms, unless supportive sufficient clinical evidence has been provided.

\section{Installation of laminar airflow is not required in new} or renovated operating rooms to prevent SSIs. (IIC) 


\section{Recommendations for post-operative wound management}

Unfortunately, there is a lack of high-quality studies comparing various strategies of post - operative wound management and this certainly an area for further focused research. Aseptic technique should be used when undertaking wound dressings and wound management. Choice of dressing will depend on patient and wound needs, i.e. exudate level, wound depth, need for conformability, antimicrobial efficacy, odor control, ease of removal, safety and patient comfort [49-52].

\section{Primary vacuum dressings or Negative Pressure} Wound Therapy (i.e. for clean-contaminated and contaminated surgeries) and silver-based dressings have mixed results and individualized decisions on their use are suggested. Routine use for prevention of SSI is not recommended. (IIC)

\section{Conclusion}

We recommend hospitals in the Asia Pacific region that have high surgical site infection rates to consider reviewing their practices in accordance with the Guidelines for the Prevention of Surgical Site Infections to identify areas for improvement. We have chosen not to identify variables for a bundle. Instead, a gap analysis is recommended comparing current practices with the various recommendations in the guidelines. This should then be followed by a process improvement plan using the approach described in the APSIC Guide for Prevention of Central Line Associated Bloodstream Infections (CLABSI) to close the gaps identified [53].

Further studies are needed to demonstrate costeffectiveness of prevention of SSIs using the process improvement approach, especially in a resource constrained setting.

\section{Abbreviations}

ABHR: Alcohol-based hand rub; APSIC: Asia Pacific Society of Infection Control; ASTM: American Society for Testing and Materials; CDC: Center for Disease Control and Prevention; CHG: Chlorhexidine; CLABSI: Central line associated blood stream infection; EN: European Norms; HbA1C: Hemoglobin A1C; LMIC: Low Middle Income Countries; MBP: Mechanical bowel preparation; MRSA: Methicillin resistant Staphylococcus aureus; NHSN: National Healthcare Safety Network; NICE: National Institute for Health and Care Excellence; RCT: Randomized controlled trials; SEA: South East Asia; SSI: Surgical site infection; USA: United States of America; VRSA: Vancomycin resistant Staphylococcus aureus; WHO: World Health Organization

\section{Acknowledgements}

We acknowledge support through an educational grant from 3 M Asia Pacific. APSIC acknowledges the help of Dr. Robert G. Sawyer, Professor of Surgery and Medical Engineering Chair, Department of Surgery Western Michigan University Homer Stryker MD School of Medicine; and Dr. Steven M. Gordon, Chairman, Department of Infectious Disease, Professor of Medicine, Cleveland Clinic for reviewing the document and giving their valuable comments and feedback.

\section{Endorsed by}

1. Association Infection Prevention Control Nurse Indonesia

2. Chinese Society for Infection Control Sector, Chinese Preventive Medicine Association, China

3. Ho Chi Minh City Infection Control Society (HICS)

4. Hong Kong Infection Control Nurses Association (HKICNA)

5. Infection Control Society of Taiwan (ICST)

6. Infection Control Association of Singapore (ICAS)

7. Indonesian Society of Infection Control (INASIC)

8. National Nosocomial Infection Control Group of Thailand

9. Persatuan Kawalan Infeksi dan Antimikrobial Kota Kinabalu Sabah (PKIAKKS), Borneo

10. Korean Surgical Infections Society, South Korea

\section{Authors' contributions}

AA reviewed and authored the topics of pre-operative baths, MRSA screening and decolonization, and surgical skin preparation, surgical prophylaxis. AW reviewed and authored the topics of epidemiology, antimicrobial impregnated sutures and postoperative wound management. AzA reviewed and authored the topic of glycemic control. HYL reviewed and authored the topics of risk factors for SSI, mechanical bowel preparation and oral antibiotics for elective colorectal surgery, and oxygenation. KM reviewed and authored the topics of surveillance of surgical site infections, normothermia, normovolemia and hair removal. KY reviewed and authored the topics of irrigation, drapes and laminar airflow. MLL is the lead author of this manuscript and chaired the workgroup discussion. She also reviewed and authored the topics on surgical hand preparation, nutrition and wound protector. Both AzA and KY reviewed and authored the topics of vancomycin powder. All authors read and approved the final manuscript.

\section{Funding}

We acknowledge support through an educational grant from 3 M Asia Pacific in the development of the guidelines. $3 \mathrm{M}$ is not involved in providing input to the guidelines. The guidelines were strictly developed with input from the authors.

\section{Availability of data and materials}

The authors reviewed previously published guidelines and recommendations relevant to each section and performed computerized literature searches using PubMed.

Ethics approval and consent to participate

Not applicable.

\section{Consent for publication}

Not applicable.

\section{Competing interests}

The authors declare that they have no competing interests.

\section{Author details}

${ }^{1}$ Infection Prevention \& Epidemiology, Singapore General Hospital, Singapore 169608, Singapore. ${ }^{2}$ Infectious Diseases, Division of Infectious Diseases, Thammasat University Hospital, Khlong Nueng, Thailand. ${ }^{3}$ Orthopaedic Surgery, National Orthopaedic Centre of Excellence for Research and Learning (NOCERAL), Faculty of Medicine, University of Malaya, Kuala Lumpor, Malaysia. ${ }^{4}$ Division of Clinical Laboratory and Infection Control Yamagata University Hospital, Yamagata, Japan. ${ }^{5}$ Surgery, Medical College, Kyung Hee University Center, Gangdong-gu, South Korea. Infectious Diseases and Infection Control, Aster Medcity, Kochi, India. ${ }^{7}$ Orthopaedic Surgery, Kanto Rosai Hospital, Kawasaki, Japan.

Received: 29 May 2019 Accepted: 31 October 2019

Published online: 12 November 2019

\section{References}

1. Condon RE, Schulte WJ, Malangoni MA, Anderson-Teschendorf MJ. Effectiveness of a surgical wound surveillance program. Arch Surg. 1983; 118(3):303-7.

2. Haley RW, Culver DH, White JW, Morgan WM, Emori TG, Munn VP, et al. The efficacy of infection surveillance and control programs in preventing nosocomial infections in US hospitals. Am J Epidemiol. 1985;121(2):182-205. 
3. Mu Y, Edwards JR, Horan TC, Berrios-Torres SI, Fridkin SK. Improving riskadjusted measures of surgical site infection for the national healthcare safety network. Infect Control Hosp Epidemiol. 2011;32(10):970-86.

4. Edmiston CE Jr, Lee CJ, Krepel CJ, Spencer M, Leaper D, Brown KR, et al. Evidence for a standardized preadmission showering regimen to achieve maximal antiseptic skin surface concentration of chlorhexidine gulconate, $4 \%$ in surgical patients. JAMA Surg. 2015;150:1027-33.

5. Nelson RL, Gladman E, Barbateskovic M. Antimicrobial prophylaxis for colorectal surgery. Cochrane Database Syst Rev. 2014;5:CD001181.

6. Tanner J, Norrie P, Melen K. Preoperative hair removal to reduce surgical site infection. Cochrane Database Syst Rev. 2011;11:CD004122.

7. Lefebvre A, Saliou P, Lucet JC, Mimoz O, Keita-Perse O, Grandbastien B. Et al; French study Group for the Preoperative Prevention of surgical site infections. Preoperative hair removal and surgical site infections: network meta-analysis of randomized controlled trials. J Hosp Infect. 2015;91(2):100-8.

8. Pofahl WE, Goettler CE, Ramsey KM, Cochran MK, Nobles DL, Rotondo MF. Active surveillance screening of MRSA and eradication of the carrier state decreases surgical site infections caused by MRSA. J Am Coll Surg. 2009;208:981-6.

9. Van Rijen M, Bonten M, Wenzel R and Kluytmans J. Mupirocin ointment for preventing Staphylococcus aureus. Cochrane Database Syst Rev 2008;CD006216.

10. Allegranzi B, Zayed B, Bischoff $P$, Kubilay NZ, de Jonge $S$, de Vries F, et al. New WHO recommendations on intraoperative and postoperative measures for surgical site infection prevention: an evidence-based global perspective. Lancet Infect Dis. 2016;16:e288-303.

11. WHO guidelines on hand hygiene in health care. Geneva: World Health Organization, 2009. http://apps.who.int/iris/bitstream/10665/44102/1/ 9789241597906_eng.pdf (accessed Sep 9, 2017).

12. Parienti JJ, Thibon P, Heller R, Le Roux $Y$, von Theobald P, Bensadoun $H_{,}$ et al. Hand-rubbing with an aqueous alcoholic solution vs traditional surgical hand-scrubbing and 30-day surgical site infection rates: a randomized equivalence study. JAMA. 2002;288:722-7.

13. Tanner J, Dumville JC, Norman G, Fortnam M. Surgical hand antisepsis to reduce surgical site infection. Cochrane Database Syst Rev. 2016;1:CD004288.

14. Dumville JC, McFarlane E, Edwards P, Lipp A, Holmes A, Liu Z. Preoperative skin antiseptics for preventing surgical wound infections after clean surgery. Cochrane Database Syst Rev. 2015;4:CS003949.

15. Anderson DJ, Podgery K, Berrios-Torres SI, Bratzler DW, Dellinger EP, Greene $L$, et al. Strategies to prevent surgical site infections in acute care hospitals: 2014 update. Infect Control Hosp Epidemiol. 2014;36:605-27.

16. Maiwald M, Chan ES. The forgotten role of alcohol: a systematic review and meta-analysis of clinical efficacy and perceived role of chlorhexidine in skin antisepsis. PLoS One. 2012;7:e44277.

17. Anderson DJ, Podgorny K, Berrios-Torres SI, Bratzler DW, Dellinger EP, Greene L, et al. Strategies to prevent surgical site infections in acute care hospitals: 2014 update. Infect Control Hosp Epidemiol. 2014;35:605-27.

18. Ban KA, Minei JP, Laronga C, Harbrecht BG, Jensen EH, Fry DE, et al. American College of Surgeons and surgical infection society: surgical site infection guidelines, 2016 update. J Am Coll Surg. 2017;224:59-71.

19. Fujitani K, Tsujinaka T, Fujita JMiyashiro I, Imamura H, Kimura Y, et al. Prospective randomized trial of preoperative enteral immunonutrition followed by elective total gastrectomy for gastric cancer. Br J Surg. 2012;99:621-9.

20. Gianotti L, Braga M, Nespoli L, Radaelli G, Beneduce A, Di Carlo V. A randomized controlled trial of preoperative oral supplementation with a specialized diet in patients with gastrointestinal cancer. Gastroenterology. 2002;122:1763-70

21. Klek S, Sierzega M, Szybinski P, Szczepanek K, Scislo L, Walewska E, Kulig J. The immunomodulating enteral nutrition in malnourished surgical patients - a prospective, randomized, double-blind clinical trial. Clin Nutr. 2011;30:282-8.

22. de Luis DA, Izaola O, Cuellar L, Terroba MC, Aller R. Randomized clinical trial with an enteral arginine-enhanced formula in early postsurgical head and neck cancer patients. Eur J Clin Nutr. 2004;58:1505-8.

23. American Diabetes Association. Standards of Medical Care in Diabetes-2013. Diabetes Care. 2013 Jan; 36(Suppl 1): S11-S66. Published online 2012 Dec 10. doi: https://doi.org/10.2337/dc13-S011

24. Latham R, Lancaster AD, Covington JF, Pirolo JS, Thomas CS Jr. The association of diabetes and glucose control with surgical-site infections among cardiothoracic surgery patients. Infect Control Hosp Epidemiol. 2001;22(10):607-12.

25. Han H-S, Kang S-B. Relations between long-term glycemic control and postoperative wound and infectious complications after Total knee Arthroplasty in type 2 diabetics. Clinics in Orthopedic Surgery. 2013;5:118-23.
26. Al-Niaimi AN, Ahmed M, Burisha N, Chackmakchy SA, Seo S, Rose S, et al. Intensive postoperative glucose control reduces the surgical site infection rates in gynecologic oncology patients. Gynecol Oncol. 2015; 136:71-6.

27. Takesue Y, Tsuchida T. Strict glycaemic control to prevent surgical site infections in gastroenterological surgery. Ann Gastroenterol Surg. 2017;1:52-9.

28. Jeon CY, Furuya EY, Berman MF, Larson EL. The role of pre-operative and post-operative glucose control in surgical-site infections and mortality. PLoS ONE. 7(9):e45616. https://doi.org/10.1371/journal.pone.0045616.

29. Melling AC, Ali B, Scott EM, Leaper DJ. Effects of preoperative warming on the incidence of wound infection after clean surgery: a randomised controlled trial. Lancet. 2001;358(9285):876-80.

30. Kurz A, Sessler DI, Lenhardt R. Perioperative normothermia to reduce the incidence of surgical-wound infection and shorten hospitalization. Study of wound infection and temperature group. N Engl J Med. 1996;334(19):1209-15.

31. Pu Y, Cen G, Sun J, Gong J, Zhang Y, Zhang M, et al. Warming with an underbody warming system reduces intraoperative hypothermia in patients undergoing laparoscopic gastrointestinal surgery: a randomized controlled study. Int J Nurs Stud. 2014;51(2):181-9.

32. Madrid E, Urrútia G, Roqué i Figuls M, Pardo-Hernandez H, Campos JM, Paniagua $P$, et al. Active body surface warming systems for preventing complications caused by inadvertent perioperative hypothermia in adults. Cochrane Database Syst Rev. 2016;4:CD009016.

33. Dalfino L, Giglio MT, Puntillo F, Marucci M and Brienza N. Haemodynamic goal-directed therapy and postoperative infections: earlier is better. A systematic review and meta-analysis. Crit Care. 2011;15(3):R154.

34. Chappell D, Jacob M, Hofmann-Kiefer K, Conzen P, Rehm M. A rational approach to perioperative fluid management. Anesthesiology. 2008;109:723-40.

35. Global guidelines on the prevention of surgical site infection $(\mathrm{WHO})$ Available at : http://www.who.int/gpsc/ssi-guidelines/en/

36. National Institute for Health and Care Excellence, Surgical site infections: prevention and treatment https://www.nice.org.uk/guidance/cg74

37. Leaper DJ, Edmiston CE Jr and, Holy CE. Meta-analysis of the potential economic impact following introduction of absorbable antimicrobial sutures. British Journal of Surgery, first published: 17 January 2017. DOl: https://doi.org/10.1002/bjs.10443

38. Casey AL, Karpanen TJ, Nightingale P, Conway BR, Elliott TS. Antimicrobial activity and skin permeation of iodine present in an iodine-impregnated surgical incise drape. J Antimicrob Chemother. 2015;70:2255-60.

39. Johnston DH, Fairclough JA, Brown EM, Morris R. Rate of bacterial recolonization of the skin after preparation: four methods compared. $\mathrm{Br}$ J Surg. 1987;74:64.

40. Rezapoor M, Tan T, Maltenfort MG, Parvizi J. Incise draping reduces the rate of contamination of the surgical site during hip surgery: a prospective. Randomized Trial J Arthroplasty. 2018 Jun;33(6):1891-5.

41. National Institute for health and clinical excellence. Surgical site infection: prevention and treatment of surgical site infection. 51-54. Clinical Guideline October 2008.

42. Webster $\mathrm{J}$ and Alghamdi A. Use of plastic adhesive drapes during surgery for preventing surgical site infection. Coch Database Syst Rev 2015, Issue 4. Art. No.: CD006353.

43. Baier P, Kiesel M, Kayser C, Fischer A, Hopt UT, Utzolino S. Ring drape do not protect against surgical site infections in colorectal surgery: a randomised controlled study. Int J Color Dis. 2012;27:1223-8.

44. Mihaljevic AL, Schirren R, Özer M, Ottl S, Grün S, Michalski CW, et al. Multicenter double-blinded randomized controlled trial of standard abdominal wound edge protection with surgical dressings versus coverage with a sterile circular polyethylene drape for prevention of surgical site infections: a CHIR-net trial (BaFO; NCT01181206). Ann Surg. 2014;260:730-7.

45. Pinkney TD, Calvert M, Bartlett DC,Gheorghe A, Redman V, Dowswell G, Hawkins W, et al, and the West Midlands Research Collaborative, and the ROSSINI Trial Investigators. Impact of wound edge protection devices on surgical site infection after laparotomy: multicentre randomised controlled trial (ROSSINI Trial). BMJ 2013; 347: f4305.

46. Berríos-Torres SI, Umscheid CA, Bratzler DW, Leas B, Stone EC, Kelz RR, et al. Healthcare infection control practices advisory committee. Centers for Disease Control and Prevention guideline for the prevention of surgical site infection, 2017. JAMA Surg. 2017;152(8):784-91.

47. Bakhsheshian J, Dahdaleh NS, Lam SK, Savage JW, Smith ZA. The use of vancomycin powder in modern spine surgery: systematic review and metaanalysis of the clinical evidence. World Neurosurg. 2015;83(5):816-23. 
48. Evaniew N, Khan M, Drew B, Peterson D, Bhandari M, Ghert M. Intrawound vancomycin to prevent infections after spine surgery: a systematic review and meta-analysis. Eur Spine J. 2015;24(3):533-42.

49. World Union of Wound Healing Societies (WUWHS) Consensus Document. Closed surgical incision management: understanding the role of NPWT. Wounds International, 2016.

50. Dumville JC, Coulthard P, Worthington HV, Riley P, Patel N, Darcey J, et al. Tissue adhesives for closure of surgical incisions. Cochrane Database Syst Rev. 2014;11:CD004287.

51. Bonds AM, Novick TK, Dietert JB, Araghizadeh FY, Olson CH. Incisional negative pressure wound therapy significantly reduces surgical site infection in open colorectal surgery. Dis Colon Rectum. 2013;56:1403e1408.

52. Dickinson Jennings C, Culver Clark R, Baker JW. A prospective, randomized controlled trial comparing 3 dressing types following sternotomy. Ostomy Wound Manage. 2015;61:42-9.

53. Ling ML, Apisarnthanarak A, Jaggi N, Harrington G, Morikane K, Thu LTA et al. Guide for prevention of Central Line Associated Bloodstream Infections (CLABSI). Antimicrobial Resistance and Infection Control (2016) 5:16.

\section{Publisher's Note}

Springer Nature remains neutral with regard to jurisdictional claims in published maps and institutional affiliations.

Ready to submit your research? Choose BMC and benefit from:

- fast, convenient online submission

- thorough peer review by experienced researchers in your field

- rapid publication on acceptance

- support for research data, including large and complex data types

- gold Open Access which fosters wider collaboration and increased citations

- maximum visibility for your research: over $100 \mathrm{M}$ website views per year

At BMC, research is always in progress.

Learn more biomedcentral.com/submissions 